\title{
Tactility and the Body in Early Chinese Medicine
}

\section{Elisabeth Hsu}

University of Oxford

\section{Argument}

If visual inspection of corpses was central to the development of anatomy in modern Europe, one may ask which of the senses was important for the emergence of the predominant currents of scholarly medical knowledge and practice in third- and second-century B.C.E. China? This article argues that it was tactile perception prompted by a tactile exploration of living bodies. The evidence, derived from a close reading of the Mawangdui medical manuscripts, the 105th chapter of the Records of the Historian (Shi ji 史記), and selected passages from the Huang Di's Inner Canon (Huang Di nei jing 黄帝入經), points to three important trends: first, the tactile exploration of the extremities led to a rich vocabulary of compound words for pain (tong 痛) as localized in specific body parts; second, the tactile exploration of the mai 脈 (vessels/pulses) gave rise to an even richer vocabulary on qualities of touch in pulse diagnostics; and third, the tactile exploration of the abdomen led to the assessment of the quality of the internal viscera (zang 臟) with words that generally were used for describing the tactile quality of skin and flesh. This finding may appear surprising in the light of later developments during the dynastic history of Chinese medicine where tactile exploration of abdomen and extremities would appear unseemly. The author suggests that extensive tactile explorations of the body were possible before Confucius' teachings became a predominant aspect of state ideology.

Scientific inquiry, while subject to institutional and political changes, is also shaped by people's sense of aesthetics, their sensitivities, and their systematic elaboration of certain forms of perception. This has variously been shown for the development of the modern natural sciences and medicine. Jessica Rifkin refers to vision as "Enlightenment's supreme sense," Jay Martin speaks of the "scopic regimes of modernity," and Michel Foucault, while outlining a discursive practice that emerged in hospitals of eighteenth-century France, has long coined the concept of the "clinical gaze" (Rifkin 2002, 10; Foucault [1963] 1989; Martin 1988). These are only a few authors, among a host of others, who suggested that new ways of seeing, morally acceptable to the emergent civil society in Europe, shaped the development of the arts and the modern sciences.

Seeing had to be learned. Such a process of "learning to see" in medical contexts, which had already begun centuries earlier in northern Italy, is vividly depicted in Rembrandt's painting of the "Anatomy Lesson by Dr. Nicholas Tulp": several gentlemen are gathered around a corpse, a corpse that has been cut open, and they 
are viewing and discussing it. Lifeless matter is meant to inform them about the living body. The gentlemen stand together in a group, they watch a performance, and their group's conversation and consensus of each having seen (with his own eyes) the same results of the performance is essential to the formation of what later became known as a "scientific fact" (Shapin 1994); these visual experiences of respectable men who can be trusted, of the cities of Amsterdam, Padua, London, and many others, were essential to the development of modern anatomy.

I do not intend to argue that the body as known through modern anatomy stands in stark contrast to the body as known in early Chinese medicine. It is not my intention to reiterate Manfred Porkert's distinction of modern biomedical anatomy and pre-modern Chinese medicine into two types, one interested in structure, the other in function; one grounded in a style of thinking that is analytic and deductive, the other in a style that is inductive and synthetic (Porkert 1974, 107). Such polar opposition, as useful as it may have been among practitioners, is unacceptably simplified, and does justice neither to anatomy nor to Chinese medicine. The reason I mention Rembrandt's painting here is that it highlights how knowledge is gained through a certain mode of perception. If visual inspection refined the science of anatomy, I ask, which mode of perception shaped the Chinese medical understanding of bodily processes?

The answer to my question is contained in the title of this article, and in what follows I intend to demonstrate that the "Chinese medical body," as known through texts dating to the Han dynasty (206 B.C.E.-220 C.E.), emerged through tactile exploration of living bodies. ${ }^{1}$ This may surprise those who know that in Late Imperial China, Chinese doctors were known for their non-invasive diagnostic methods, and would restrict them to inspection of the complexion and palpation of the wrist for taking the pulse. If the patient was female, and of elevated standing, doctors were not supposed to touch her at all; from the touch of a silk thread, bound around the woman's wrist, they should tell the disease. ${ }^{2}$

Confucian scriptures taught that mutilation was impious, and dissection was regarded as a form of mutilation. As a consequence knowledge of anatomy in Chinese medical history was very limited. This is a commonplace that recent scholarship silently accepts, although there are various text passages that report on the dissection of corpses of convicts, prisoners, and enemies (e.g. Ma 1994, 447-454). Early Chinese historians believed that Wang Mang 王莽, the founder of the Xin dynasty (9-23 C.E.), dissected corpses (Han shu 漢:書 99B, 4145-4146). They depicted him as a highly immoral character, and no one emulated him. It is also known that, in Song times (960-1279),

\footnotetext{
1 There is no one "Chinese medical body," and ideas about it varied with different authors, and changed over

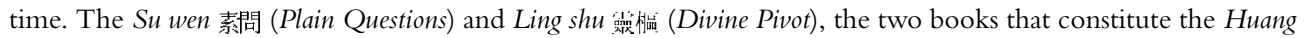

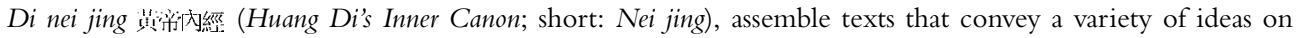
various themes of bodily concern. For a general discussion of Chinese medical bodies in the Han dynasty, see Sivin 1995; Harper 1998, 68-147; and Unschuld 2003, 124-180.

${ }^{2}$ On the multiple diagnostic procedures for women that go beyond the above stereotype, see Furth 1999 , 245-257.
} 
techniques and procedures of post-mortem investigations were developed for forensic purposes, however, generally without the help of physicians (McKnight 1981, 2426). And there is the remarkable nineteenth-century physician Wang Qingren 王清任 (1768-1831), much celebrated in the People's Republic of China (PRC), who frankly reports on his dissection of cadavers that led him to critique Chinese physicians' basic assumptions about body parts and bodily processes in his Yi lin gai cuo 醫林改錯 (Correction of Errors among Physicians) of $1830 .^{3}$ So, even though there were exceptions, as long as Confucian morals were integral to state religion, dissection was not generally done; and, as Ma Boying 馬伯奖 (1994, 452) stresses, it certainly was not turned into a performance attended by respectable members of society.

There is a sentence in Huang Di's Inner Canon 黄帝入入經 (Huang Di nei jing; short: Nei jing), in chapter 12 of the Divine Pivot (Ling shu 靈榀, 311), which mentions the word jie pou 解剖 that nowadays designates “dissection." The text passage states that in contrast to heaven and earth, which cannot be fathomed, man can be "cut open" (jie pou) and measured.

If a man of eight foot, with skin and flesh is alive, you can measure him from the outside by "pressing" (qie 切) and "stroking" (xun 循), and thereby obtain [the measure]; if he is dead, you can "dissect" (jie pou) him, and thereby inspect him.

“The firmness and plasticity of his viscera” (qi zang zhi jian cui 其臟之堅脆), the size of his bowels, the number of his valleys, ${ }^{4}$ the length of his "crest lines" (mai 脈), the transparency of his blood, the quantity of his $q i$ 氣 (air, breath, vapor), and among the twelve channels, the abundance of blood and the paucity of $q i$, and the paucity of blood and the abundance of $q i$, as well as the abundance of blood and $q i$, and the paucity of blood and $q i$, all have their "norm" (da shu 人数).

This text passage surprises current scholarship for it seems to advocate dissection. Indeed, doctors in the PRC, intent on proving that Chinese medicine is "scientific" (kexuehua 科學化), have shown that the physicians who composed and compiled the Nei jing were interested not only in subtle "humoral" processes and functional transformations within the body, but also in tangible body parts and their

\footnotetext{
${ }^{3}$ Any recent history of Chinese medicine will mention Wang Qingren, e.g. Unschuld 1980, 173-5, or Ma 1994, 452-54. Translations of Western dissections were done before his time, but kept at the Imperial Library, and not known to him (Andrews 1994, 150).

${ }^{4}$ Modern Chinese medical historians render this phrase as "the quantity of his food intake," i.e. they interpret $g u$ 谷 to mean “cereals” (e.g. Nanjing zhongyi xueyuan zhongyixi 1986, 131). However, gu may mean "valley” or "gorge," as opposed to mai, mentioned in the following phrase, which can refer to the "crest lines of mountain ranges." In that case, gu and mai invoke a body landscape. That mai stand out is given in the description of frightened horses in a pre-dynastic text, the Zuo zhuan 头估 (Zuo Tradition): “When they [the horses] become confused, they will get all excited. Their timorous blood will flush all their bodies, and their veins will everywhere stand out" (Legge [1871] 1991, 168). See also Harper 1998, 82.
} 
measurements. ${ }^{5}$ This would suggest that Chinese physicians in antiquity were indeed interested in measuring dead matter in corpses.

In an attempt to solve the problem that the above sentence poses, one might argue that the word jie pou does indeed suggest that dissection was advocated, however, not between the Han dynasty, when the Ling shu (Divine Pivot; then called Zhen jing 針經) was compiled, though then known by another name, and the tenth century, whence we have the first extant manuscript. It took place, rather, in the time period before Confucianism became an ideology of the state. In other words, it probably was in the Warring States period (475-221 B.C.E.) that the above sentence was first formulated. ${ }^{6}$

Regardless of whether or not corpses were cut open before Confucian teachings became part of state ideology, the material presented below suggests that doctors of late pre-dynastic and early dynastic times were "hands-on-physicians" in that they used touch extensively in their investigation of the living body. The parts of the body that they appear to have tactually explored were, first, the four extremities, second, the mai (conduits, ducts, channels, vessels, crests), and third, the abdomen. The aspects of human existence that interested them in these respective body parts were: "pain" (tong 痛), "impulsions" (qi), ${ }^{7}$ and the "firmness and plasticity" (jian cui) of flesh and viscera.

The texts on which my argument builds are, first, the "vessel texts" in the Mawangdui 馬王堆 manuscripts (before 168 B.C.E.); second, the twenty-five medical case histories recorded in the "Memoir of the Master of the Granary" (Canggong zhuan 倉公傅) in chapter 105 of the Records of the Historian (Shi ji 史記) by Sima Qian 司䭴遷 (ca. 90 B.C.E.); and third, text excerpts from the Nei jing |入經 (circa first to second century C.E.). The two former textual sources date to a time before statesponsored text compilation projects led towards a standardization of medicine; the third was compiled in the Han dynasty, but the textual material often dates to earlier periods.

In what follows, summaries of the three above texts are given first, followed by a brief excursus into early textual fragments which indicate that tactility was indeed a mode of perception developed early in Chinese medicine. Thereafter, the discussion focuses on, first, the tactile exploration of the limbs and the systematic assessment of pain, as recorded in the Mawangdui "vessel texts"; second, the tactile exploration of the mai and the systematization of "impulsions" (qi) in the 105th chapter of the Shi ji;

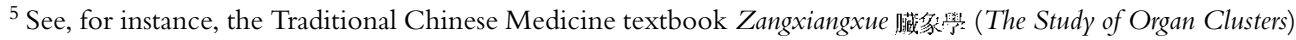
that provides many quotes from the medical archive to underline the anatomical knowledge of pre-modern physicians (Yunnan zhongyi xueyuan 1988, 19, 34, 35).

${ }^{6}$ The enigma of Ling shu 12 cannot be solved here; it is not of further relevance to my argument.

${ }^{7}$ The term $q i$, approximated by terms like air, breath, and vapor, is difficult to grasp. The rendering of $q i$ as "impulsion" is very context-specific and unusual, it applies to the notion of $q i$ in compound words in the first ten case histories in Shi ji 105. In Han dynasty texts, qi is stuff that permeates the universe and also has agency, i.e. it can cause transformations (Sivin 1995). The approximation of $q i$ as "impulsion" is meant to stress its latter aspect.
} 
and third, the tactile exploration of the abdomen and the sensitivity developed for the "firmness and plasticity" of flesh and viscera, as text passages of the Nei jing suggest.

\section{The texts}

The texts known as the "Mawangdui medical manuscripts" were found in a lacquer box unearthed in 1973 from a tomb closed in 168 B.C.E. The occupant of the Mawangdui tomb nr. 3 (with whom these texts were buried) was one of the sons of the occupant of tomb nr. 2, Li Cang 利荅, who had the aristocratic rank of "Lord of Dai" and was a chancellor of the Kingdom of Changsha 長沙國 in present-day Hunan province. The manuscripts thus represent valued goods of the Western Han nobility; they testify to the existence of personal libraries and, according to Donald Harper, a certain "bibliophilia" among the literate elite (Harper 1998, 36-41). The entire corpus comprises about thirty manuscripts, and on them are written about forty-five texts, some of which are recorded in two different recensions. When modern researchers decided to arrange the manuscripts according to different themes, they classified some as "medical" for lack of a better term, being well aware that their scope, ranging from methods for prognosticating death to sexual techniques, does not fit our modern concept of "medicine." What is now known as the "medical corpus" comprises seven manuscripts with fourteen texts, and the number of its characters amounts to about eighteen per cent of the 125,000 characters in the entire corpus. ${ }^{8}$ The "vessel texts" (i.e. texts I.A and I.B in Harper 1998, whereby I.B has two variants) concern mai (vessels), their course on the body surface and their disorders. They belong among the most researched texts of early Chinese medicine (Bridgman 1981; Keegan 1988; Ma 1992; Harper 1998; Han 1999; Li 2000).

The 105th chapter of the Shi ji concerns the biography of two physicians. The first, called Qin Yueren 秦越人, but better known by the name Bian Que 扁鹊, could see through walls and resuscitate the dead, after ingestion of a potion given to him by a stranger. The second, by name Chunyu Yi 淳于意, was known by his title Canggong 倉公 “Master of the Granary," which he had obtained as an official of the kingdom of Qi 齎 in the early Western Han dynasty (206 B.C.E.-8 C.E.). Around the age of thirty-five (180 B.C.E.), he enrolled for three years in an apprenticeship and started to practice medicine. Bian Que and the three case histories recorded in his biography have frequently been cited in Chinese medical history and today they are part of people's common knowledge, even folklore. Later physicians also referred to Canggong, but his biography and the twenty-five case histories contained in it are not as widely known. As I have demonstrated in my Habilitation The Telling Touch (Hsu 2001a), the first ten case histories contain sufficient detail to recognize in them a particular form of pulse diagnostics, a form that in many aspects was later discontinued. These medical case

\footnotetext{
${ }^{8}$ For a detailed account, see Harper 1998, 14-30.
} 
histories thus contain the earliest fairly extensive information on early Chinese pulse diagnostics, and only few fragments date to an earlier period (cited below).

The Nei jing constitutes a compilation of texts that are sometimes significantly older than the compilation itself. ${ }^{9}$ Chapter 10 of the Ling shu, the second book of the Nei jing, for instance, records the Mawangdui "vessel texts" I.A and I.B generally in a strongly modified form, yet in places also verbatim. It is obvious that the texts which the Nei jing thematically juxtaposes often contradict each other, and one may safely assume that they present different currents of medical knowledge and practice; the Nei jing therefore cannot be seen as representing one single medical doctrine. Rather it contains an assembly of knowledge from a variety of different medical lineages. The medical current that is most prominent in the edition of the first book, the $S u$ wen 素问 (Plain Questions), is what Paul Unschuld (1980), in line with Manfred Porkert (1974), has called the "medicine of systematic correspondences." It is grounded in a conception of the body that does not distinguish between mind and matter, and that gives great attention to the atmospheric, i.e. qi.

\section{The question}

The question that interests us here is why Chinese physicians of early dynastic times became interested in subtle changes that are not directly visible to the onlooker. How can we explain their scientific interest in subtle, often invisible changes? While every doctor uses the five senses when investigating the condition of a patient, we can assume that certain modalities of perception are systematically refined through particular cultural practices and scientific cultures. It was vision in Enlightenment Europe, was it tactility in the context of medicine in late pre-dynastic and early dynastic times in China?

Two textual fragments in the Mawangdui medical manuscripts belong among the earliest testimony of pulse diagnostics, and hence give hints that Chinese physicians had already developed a heightened sensitivity for touch in early dynastic times. The first in text I.A (CC 21-22) concerns the prognostication of death. It may not have been coincidence that physicians developed a method for prognosticating death at a very early stage in history because it would prevent them from delivering treatment to a patient who would die in any case. By treating patients who would live, the efficacy of treatment they agreed to deliver was enhanced, and along with it, the physicians' trustworthiness (Lloyd 1970, 52). Notably, this practice of prognosticating the death of an individual patient arose in a court culture that cultivated divination and prognostication in the public domain.

\footnotetext{
${ }^{9}$ On the composition and the dating of the Huang Di nei jing, see Yamada 1979, Keegan 1988, Sivin 1993, and Unschuld 2003. Unschuld suggests that the extant Huang Di nei jing Su wen builds on texts compiled during the Eastern Han [25-220 C.E.] (Unschuld 2003, 5).
} 
If, when stroking the mai, it is as if three persons together were triply pounding [millet], death occurs within three days.

If the mai is severed, as if it were the moment of eating [and swallowing down] a meal, death occurs within three days. ${ }^{10}$

In the above two sentences, the tactile perception was assessed with a metaphor, or more precisely, with a simile. Interestingly, this method of describing the tactile experience of pulses was retained in the later literature on pulses indicative of death (Mai jing 脈經 5, 161-162; Hsu 2000 and 2001c), but shall not concern us further here.

The second case, text I.C (CC 81), seems to differentiate between a variety of different pulse qualities. The text is seriously damaged, and the only word one can decipher is "depleted" ( $x u$ 虛). Nevertheless, it seems that by the comparison of one pulse quality with another, doctors determined whether or not the respective mai was in a pathological state. ${ }^{11}$

$\mathrm{x}$ if depleted then it governs an illness, the other mai $\mathrm{x}$, this one $\mathrm{x} x$, then $\mathrm{x} x$, the other mai $\mathrm{x} \times \mathrm{x} \times \mathrm{x} \times \mathrm{x} \times \mathrm{x} \times \mathrm{x} \times \mathrm{x}$.

The use of adjectives will become the predominant way in which the tactile perception of pulses is assessed in later medical writings. The Canon of Sphygmology (Mai jing) of circa 280 C.E., for instance, lists twenty-four adjectives for assessing twenty-four pulse qualities, each indicative of a variety of disorders. ${ }^{12}$

The above two text passages are mentioned here because they testify to an early interest in pulse diagnostics and tactility. As we will see below, there were yet other modes of distinguishing between different pulse qualities in Han times. Before discussing those, let us turn to the Mawangdui "vessel texts."

\section{The tactile exploration of the extremities}

The Mawangdui "vessel texts" contain a rich vocabulary for referring to various parts of the body trunk and the limbs, and for designating different bodily sites of pain. The

\footnotetext{
10 The translation is informed by Harper 1998, 200, slightly modified. Perhaps the second simile refers to pulsations of the arteries of the neck, which cannot be felt and are "severed" during the moment of swallowing. Early Chinese pulse diagnostics was not performed exclusively at the wrist (Kuriyama 1999, 38-39, refers to Ling shu 9, 293-294, and Su wen 9, 33, Su wen 20, 64-65).

${ }^{11}$ For translation of the reconstructed text, see Harper 1998, 216-217. It is considered to describe three pairs of pulse qualities, each assessed by an adjective.

12 There are variants to this number; see, for instance, the texts on sphygmology in the Dunhuang medical

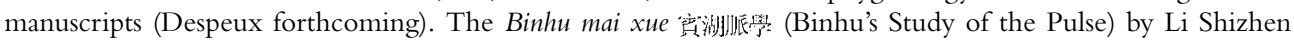

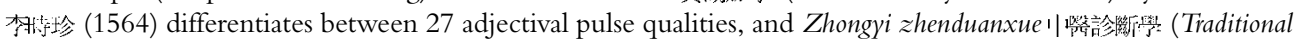
Chinese Medical Diagnosis), edited by Deng Tietao 㑪鐵澍 (1984) records 28. The term “adjective” in this article is used as a short-hand for what in literary Chinese is more accurately identified as a "static verb."
} 
most central notion to these texts is, however, mai. In later medical writings, the term mai was sometimes used interchangeably with the term jing 經 (tract, channel, conduit, duct), and in contemporary Chinese medicine, jing refers to the twelve channels on the surface of the body ( $\mathrm{Li}$ 1984). However, it would be wrong to leap onto the affinity of mai and jing when introducing the concept mai in the "vessel texts." In early texts, the mai come and go, they sometimes visibly protrude, and at others are submerged.

The term mai has a text-structuring function in the "vessel texts," I.A and I.B. There are eleven mai, six “foot” ( $z u$ 足) mai and five “forearm” ( $b i$ 臂) mai, according to which the text is divided into eleven sections. One of the main characteristics of mai is that they are qualified by the variables yin and yang, and those are differentiated into yang ming 陽明 (yang brilliance), tai yang 太陽 (great yang), shao yang 少陽 (lesser yang) and tai yin 太陰 (great yin), shao yin 少陰 (lesser yin), jue yin 蹶陰 (attenuated yin). These concepts testify to a certain cosmological speculation not found in other Mawangdui medical texts such as text I.E, for instance, which lists recipes for treating fifty-two different disorders. The two "vessel texts" differ in their ordering of the eleven mai: in text I.A, forearm and foot, i.e. the upper versus the lower limbs, are the super-ordinate devices, and in text I.B, they are yin 陰 and yang 陽.

Each of the eleven textual sections on a particular mai is divided into two parts: one describes the course of the mai, mostly along the extremities, and the other contains a list of disorders. The vocabulary used for describing the course of the mai in the first part refers to many terms for specific body parts, and conveys a static view of a bodily architecture. The particular body parts described are often on the limbs. The disorders described in the second part range from symptoms to syndromes, and testify to a rich nosological vocabulary. As in the case of the body parts, it is difficult to know the exact referential meanings of these terms.

An example of how one of the eleven sections on the mai is structured into two parts is given below (Harper 1998, 196-197, CC 10-12).

Foot yang brilliance vessel [mai]

It follows along the shin. Ascending, it penetrates the knee, emerges at the thigh, and presses laterally on the lesser abdomen. Ascending, it emerges at the inner edge of the breast and emerges at the throat. It presses laterally on the mouth and, ascending, goes to the nose.

The ailments: ailing from the loss of function in the middle toe; shin pain; swelling in the knee; swelling in the abdomen; pain in the inner edge of the breast; swelling in the outer part of the $[\mathrm{x}]$; cheekbone pain; stuffy nose and bloody nose; continual hotness with sweating; loss of flesh at the cuo; coldness in the center of the forehead. In all cases of ailing from these things, cauterize the Yang Brilliance vessel.

This example shows that the "vessel texts" are not only concerned with the description of a static bodily architecture, and enumerating structures of the body, as one may have been inclined to think in the first instance. More importantly, the 
“vessel texts" can be interpreted as classifying “ailments" (bing 病) into eleven different categories, whereby each category refers to one of the eleven mai. On this reading, the Mawangdui "vessel texts" would be proclaiming a new view of illness etiology. The body part mai, in text I.B, is explicitly said to be responsible for causing the disorder ${ }^{13}$ and, in text I.A, it is said to be the one that needs to be treated (with cauterization) for dealing with the disorder. ${ }^{14}$ Thus, in contrast to text I.E, where the names of the disorders represent the structuring device of the text, the etiology of the disorders may be viewed as the ordering device for text I.B and the treatment method for text I.A. In other words, ideas of illness causation have shifted. Rather than making a demon responsible for an illness, as tends to be the case in text I.E, the cause of the illness and the treatment strategy, is attributed to a body part, namely mai.

In summary, by taking mai as a text structuring device, it is possible to see that the concept of mai is linked to a new concept of illness etiology. This illness etiology localized the cause of the illness in a body part, namely mai. However, such an interpretation cannot tell us very much about the other characteristics of mai. What did the term mai designate, and why was it integrated into medical language? What was the referential reality of mai? What prompted physicians to project mai on the surface of the body?

He Zhiguo and Vivienne Lo in their discussion of a black lacquer figurine on which red lines are drawn - presumably mai - suggest that the concept of mai may have arisen in the context of self-cultivation practices. They differentiate between texts concerned with "nurturing life" practices (yang sheng 養生) and others dealing with human pathology like text I.E; and they suggest that cosmological elaboration was further developed in the former (He and Lo 1996). ${ }^{15}$

R. F. Bridgman had a similarly speculative idea, though it pointed in an entirely different direction. He suggested that mai represented trajectories that strung together painful areas (Bridgman 1981, 12). Indeed, among the different disorders mentioned, pain conditions are not infrequent (see tables $1 \mathrm{a}$ and $1 \mathrm{~b}$ ). However, evidence in favor of that idea is insufficient. ${ }^{16}$ Nevertheless, Bridgman's idea builds on two very useful observations: the authors of the "vessel texts" had an elaborate vocabulary for body parts, and a similarly elaborate one for localizing pain.

\footnotetext{
13 Text I.B distinguishes between two different forms of illness causation on each mai: shi dong ze bing 是動则病 (if this one is agitated, then one ails from ....) and qi suo chan bing 其所症 (the disorders that this one produces are ...).

${ }^{14}$ Text I.A provides an instruction on how to treat the mai: one should apply “cauterization” (jiu 众). In other words, all disorders treated by cauterization of a particular mai are grouped together.

15 The names of the eleven vessels mentioned above would suggest that the "vessel texts" are comparatively rich in cosmological speculation.

${ }^{16}$ In tables 1 and 2, those cases where the same body part is mentioned in the description of the route of the mai are marked with an asterisk. Only in a few cases is the body part transversed by a mai identical to the one considered painful, in many others not.
} 
Table 1a. Pain conditions mentioned in the eleven vessels of foot and forearm Mawangdui medical manuscripts, Text I.A (before 168 B.C.E.) (Translation based on Harper 1998, 192-202 (with minor modifications); for Chinese, see CC 1-34)

\begin{tabular}{ll}
\hline Foot tai yang vessel & calf pain* \\
buttock pain \\
waist pain \\
pain pressing laterally on the spine* \\
[lacuna] pain \\
nape pain \\
hand pain (Ma 1992: head pain) \\
eye pain* \\
pain in the outer side of the shin \\
pain in the outer side of the knee* \\
pain in the outer side of the thigh* \\
pain in the outer side of the ham \\
pain in the side* \\
[lacuna] pain \\
pain in the broken basin (clavicle) \\
pain in the zhen (back of the head)* \\
pain in front of the ear* \\
pain in the outer canthus of the eye* \\
shin pain* \\
pain in the inner side of the breast* \\
cheekbone pain \\
pain on the inside of the calf* \\
pain on the inside of the thigh* \\
pain in the abdomen crossroads and the inner side of the spine* \\
liver pain* \\
heart pain \\
pain in the inner side of the shin* \\
pain on the inside of the thigh* \\
abdomen pain \\
- \\
hoot yang ming vessel \\
heart pain* \\
pain in the side* \\
pain in the outer side of the arm \\
[lacuna] pain \\
arm tai yin vessel \\
arm shao yin vessel
\end{tabular}

* The body parts marked with an asterisk are mentioned in the description of the route of the vessel.

One may point out that pain conditions are more frequently attributed to yang vessels than to yin vessels; that pain conditions sometimes arise in the parts mentioned in the description of the course of the vessels, sometimes not; that some pain conditions like toothache are very prominently associated with a certain vessel, but others are not; 
Table 1b. Pain conditions mentioned in the eleven yin and yang vessels Mawangdui medical manuscripts, Text I.B (before 168 B.C.E.) (Translation based on Harper 1998, 203-212 (with minor modifications); for Chinese, see CC 35-71)

\begin{tabular}{|c|c|}
\hline Tai yang vessel & $\begin{array}{l}\text { if this one is moved, then: chest pain (controversial) } \\
\text { this one produces: head pain } \\
\text { nape pain* } \\
\text { back pain } \\
\text { waist pain } \\
\text { bottom pain } \\
\text { pain in the upper side (controversial) } \\
\text { calf pain }\end{array}$ \\
\hline Shao yang vessel & $\begin{array}{l}\text { if this one is agitated, then one ails from: pain in the heart and the side } \\
\text { the disorders that this one produces are: head - nape pain (controversial) } \\
\text { side pain } \\
\text { pain in all the joints } \\
\text { pain in the outer side of the ham } \\
\text { [lacuna] pain } \\
\text { pain in the fish thigh* } \\
\text { pain in the outer side of the knee }\end{array}$ \\
\hline Yang ming vessel & $\begin{array}{l}\text { if this one is agitated, then: - } \\
\text { this one produces: pain in the forehead } \\
\text { neck pain } \\
\text { breast pain* } \\
\text { pain in the heart and upper side } \\
\text { pain in the intestines }\end{array}$ \\
\hline Shoulder vessel & $\begin{array}{l}\text { if this one is agitated, then: }- \text { (controversial) } \\
\text { this one produces: neck pain } \\
\text { shoulder pain* (or: arm pain) } \\
\text { elbow pain (controversial) }\end{array}$ \\
\hline Ear vessel & $\begin{array}{l}\text { if this one is agitated, then:- } \\
\text { this one produces: pain in the outer canthus of the eye } \\
\text { cheek pain }\end{array}$ \\
\hline Tooth vessel & $\begin{array}{l}\text { if this one is agitated, then: tooth pain* } \\
\text { this one produces: tooth pain* } \\
\text { upper arm pain* }\end{array}$ \\
\hline Tai yin vessel & $\begin{array}{l}\text { if this one is agitated, then:- } \\
\text { this one produces: heart pain }\end{array}$ \\
\hline Jue yin vessel & $\begin{array}{l}\text { if this one is agitated, then: waist pain } \\
\text { this one produces: - }\end{array}$ \\
\hline Shao yin vessel & $\begin{array}{l}\text { if this one is agitated, then: - } \\
\text { this one produces: pain in the centre of the throat }\end{array}$ \\
\hline Arm tai yin vessel & $\begin{array}{l}\text { if this one is agitated, then: heart pain with throbbing* } \\
\text { pain in the broken basin } \\
\text { this one produces: chest pain } \\
\text { pain in the stomach pit } \\
\text { heart pain } \\
\text { pain in the four extremities }\end{array}$ \\
\hline Arm shao yin vessel & $\begin{array}{l}\text { if this one is agitated, then: heart pain } \\
\text { this one produces: pain in the side }\end{array}$ \\
\hline
\end{tabular}

* The body parts marked with an asterisk are mentioned in the description of the route of the vessel. 
and so on. I will not go into these details. What is of interest here is the way in which pain conditions are qualified: pain is primarily identified by its location in the body, for instance, pain in the shin, in the knee, in the thigh, in the fish thigh, in the ham, in the calf, in the buttocks, in the shoulder, in the arm, in the elbow, in the hand, in all joints, and in all four extremities. Pain conditions are evidently localized in the limbs, though not exclusively. Pain is also detected in the abdomen, the stomach pit, the intestines, the liver, the heart, the waist, the side, the back, the spine, the chest, the breast, the broken basin, the throat, the neck, the nape, the cheekbone, the teeth, the forehead, and the back of the head. Its location is further differentiated as being either inner or outer, front or center, such as pain in "the outer canthus of the eye" and "in front of the ear," or "the outer/inner side of the thigh"; in text I.A, pain on the inner side is consistently attributed to yin vessels, and pain on the outer sides to yang vessels.

This is remarkable if we consider how pain has been assessed systematically in biomedicine (Melzack and Wall 1982, 40) and in other medicines, such as Yunani Tibb in India (Pugh 1991). In both these cases, pain is primarily qualified through adjectives. The McGill questionnaire differentiates between more than seventy different qualities of pain assessed by adjectives like flickering, lacerating, burning, searing scalding, pounding, stabbing, cutting, gnawing, cramping, crushing, tiring, nagging, dull, tender, etc., and popular pain categories in Yunani Tibb are assessed by more than ten different adjectives, like catching, pinching, gripping, burning, piercing, pricking, stinging, throbbing, shooting, splitting, breaking, and bursting (in translation). To be sure, in other Mawangdui texts pain conditions are described by adjectives as well, thus pain is given as “recurrent" ( $f u$ 復) or “acute" ( $j i$ 疾). However, in the “vessel texts," all pain is qualified through its localization in a body part.

Once one notices the elaborate vocabulary for localizing pain in body parts, one wonders how physicians created it. The texts do point towards a certain cosmological elaboration in terms of yin and yang and to literary playfulness; they may even be seen to have a poetic stance, but cosmological concerns and literary playfulness alone cannot explain the richness of the vocabulary. If one reads the texts in a literal manner, they report on medical practice. They are testimonies to practice-oriented knowledge and a systematic investigation of pain. How did the physicians know where it hurt the patient? Certainly, they would observe the patient, and they would listen to the patient's complaints. In addition, it is conceivable that they would touch the patient and press on the spot where it hurt. Through interaction between doctor and patient (who would react to the pressure on a painful spot), they would localize the pain. The tactually explored body is a living body, and doctors and patients would have had to interact with each other. In contrast to visual inspection, which allows for observation from a distance, tactile perception depends on a mutual engagement between doctor and patient.

Merleau-Ponty comes to mind: "Tactile experience adheres to the surface of the body; we cannot unfold it before us and it never quite becomes an object" (MerleauPonty [1945] 1962, 316). Physicians who systematically explored the limbs and other parts of the body by touching them must have done so in close cooperation with 
the patient. Vision cannot localize pain, for painful spots cannot be seen. Naturally, it is also possible that by means of gesture, by pointing to a spot, rather than by touching it, pain can be localized. In this case, physicians would not have tactually explored the body themselves, but again they would have depended on the patient's lived experience to obtain the relevant information. Information on pain depends on the patient's subjective experience.

From this vantage point, it comes as no surprise that pain is an aspect of human experience that represents an intrinsic problem for modern biomedicine, which critically depends on visual sensitivities. As has been well established (Good et al. 1992; Jackson 1992), the correlations between physically measurable variables and the subjective experience of pain are often weak. Pain is also an experience that blurs the boundaries between object and subject, as Jackson (1994) has demonstrated so vividly, and as is particularly true for acute pain (Hsu 1994). Pain is best localized through touch, and depends on the lived experience of the patient.

In summary, building on Bridgman 1981, I observed that the authors of the Mawangdui "vessel texts" were interested in the systematic localization of pain in body parts. I could not explain whence this interest in localizing pain in body parts came, though it curiously parallels the endeavor of localizing illness causes in mai, which is a particular characteristic of the "vessel texts." Considering the intrinsic relatedness of pain and touch, I then suggested that a tactile exploration of the body led to a highly differentiated localization of pain in body parts. Such tactile exploration of the live and painfully felt body contrasts sharply with the visual inspection of corpses.

\section{The tactile exploration of the mai}

In contrast to the above argument which builds on a textual analysis combined with anthropological imagination about the medical encounter, the explicit evidence that physicians of the last three centuries B.C.E. tactually explored mai is ample. In the second part of chapter 105 in the Shi ji, there are two verbs with specific meanings that describe the activity of touching mai, namely qie 切 and xun 循; qie may mean pressing down hard, like cutting through the vessel, and xun probably means stroking along the surface of the vessel. However, it is impossible to know exactly what the referential meaning of these terms was. These forms of touching differed from those of pressing on a body part to elicit a reaction to pain from the patient in that they resulted in the doctors' own perception and identification of different tactile qualities. There are other terms, perhaps less specific in meaning, that describe palpation, most notably, the terms an 案, 按 and tan 探, ${ }^{17}$ and others, which were not exclusively used for palpating the mai.

\footnotetext{
17 These terms are mentioned in the reconstructed text by Ma 1992, 293-294, in place of the lacunae in Mawangdui Hanmu boshu zhengli xiaozu $(1985,17)$.
} 
In contemporary Chinese medicine, doctors take the pulse at the wrist, as in many other cultures. The wrist is the body part that patients can stretch out furthest from more intimate parts of the body, perhaps with exception of the hand. However, the hand is the body part that people use for actively exploring the world through touch. A doctor who touches the patient at the wrist puts the patient into a passive position. By his demonstratively active intrusion into the patient's more intimate sphere, he asserts his authority over the patient (this would seem to be the case in any cultural setting). As ECGs have shown in the biomedical context, the doctor's touch of the patient during the brief period of taking the pulse can calm down a patient and reduce the frequency of the heart beats (Autton 1989, 81-82). Perhaps, the touch at the wrist that in Chinese medicine has a diagnostic purpose simultaneously has therapeutic effects.

As already mentioned in footnote 10 , body parts other than the wrist were used for taking the pulse in early Chinese medicine. In Shi ji 105, the physician Chunyu Yi speaks of "examining the pulse" (zhen mai 診脈) at the mai kou 脈口, the "opening of the mai," which later commentators suggest may have been at wrist and ankle. ${ }^{18}$ The qualities of the pulses are assessed with adjectives of touch and they are furthermore attributed specific qualities of qi. Among the pulses assessed with adjectives of touch, I have proposed to differentiate between two different kinds (Hsu 2001a): those mentioned by a medical authority that Chunyu Yi sometimes quotes, called "Mai fa” 脈法 (The Model of the Pulse), and those which Chunyu Yi mentions when he talks about the pulse qualities otherwise. I found that generally after quoting the "Mai fa," Chunyu Yi comments on it with adjectives of his own vocabulary, i.e. he translates the implications of the quote from the "Mai fa" into his own conceptual framework and in so doing he describes the pulse qualities with different adjectives. One of the main problems of interpreting the first ten case histories was to see that the "Mai fa" adjectives and Chunyu Yi's adjectives relating pulse qualities referred to the same condition in a different vocabulary.

It was possible to locate the quotes from the "Mai fa" in various text passages of the received medical literature (Hsu 2001a, cases 1-2 and 4-6, pages 114, 118, 123, 151, 194, 228, 260), but it was very difficult to find parallels to the comments Chunyu Yi made on pulse qualities. This would suggest that the pulse lore contained in the "Mai fa" attested to knowledge cultivated within a medical lineage that later was integrated into the medical compilations like the Nei jing, the Mai jing, and others, while Chunyu Yi's pulse diagnostics, cultivated within a different medical lineage, did not enjoy the same prominence and may later have fallen into oblivion. ${ }^{19}$ There are overlaps between the two; and on these grounds, one can assume that the pulse diagnostics recorded in

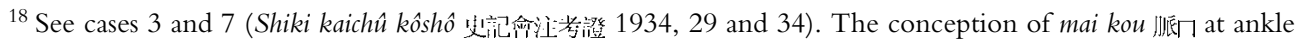
and wrist does not contrast with the descriptions of the routes of the mai in the Mawangdui "vessel texts."

${ }^{19}$ In the Nan jing 難經 (Unschuld 1986) and the texts on pulse diagnostics in the Dunhuang 敦煌 medical manuscripts (Despeux forthcoming), there are parallels to Chunyu Yi's pulse diagnostics.
} 
Table 2. Pulse qualities in terms of qi (Chunyu Yi's vocabulary) Shi ji, chapter 105 (ca 90 B.C.E.)

\begin{tabular}{|c|c|c|}
\hline gan qi 小梠 & - qi [coming] from the liver & case 1 \\
\hline xin qi 心穕 & - qi [coming] from the heart & case 2 \\
\hline 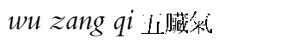 & - qi [coming] from the five viscera & case 3 \\
\hline shui qi 水冞 & - water qi & case 4 \\
\hline feng $q i$ 夙乐 & - wind qi & case 5 \\
\hline (pang guang qi 谤胱氷 & - qi [coming] from the bladder) & \\
\hline fei qi 肺积 & - qi [coming] from the lungs & case 6 \\
\hline 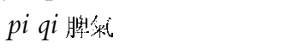 & - qi [coming] from the spleen & case 7 \\
\hline jia qi 非乘 & - qi [coming] from conglomerations & \\
\hline nei feng $q i$ 闪秫尔 & - internal wind $q i$ & case 8 \\
\hline feng $q i$ 㽍苏 & - wind $q i$ & case 9 \\
\hline (yin qi陵秘 & - yin qi) & \\
\hline jue yin zhi dong 跉给之動 & - agitation of the ceasing yin & case 10 \\
\hline
\end{tabular}

the "Mai fa" and Chunyu Yi's pulse diagnostics were closely related but nevertheless distinct.

Needless to say, it is impossible to know the referential meaning of the adjectives recorded in the "Mai fa" as well as those Chunyu Yi himself used for describing the pulse qualities. In some cases, these adjectives of touch allude to general cosmological categories, such as the "murky" ( $z$ huo 濁) and the "still” (jing 青新) in case 1 (Graham $1986,32)$. In other cases, one wonders whether the adjective of touch describes also an aspect of the pathological process within the body. Thus, a "slippery" (hua 滑) pulse was indicative of a disorder called "penetrating wind" (dong feng 迵風) with symptoms of acute diarrhea, or: a pulse that "came with difficulty" (qi lai nan 其來難) indicated that the patient had difficulties in urinating (cases 8 and 10). Some adjectives seem to relate to the size of the viscus inside the body, thus the tactile perception of a "large" ( $d a$ 人) pulse relates to the "bladder" (pao 脬, pang guang 膀脱), of which one knew that it was elastic and could be enlarged like a balloon (case 5). There is no one single principle that can explain the choice and connotations of these adjectives.

In general, touch escapes verbal assessment, and in most cases, it can only be approximated with words that are taken from other realms of experience than the tactile one. So far we have seen that in Chinese pulse diagnostics the tactile experience was described with similes and adjectives. There is yet another mode in which it was assessed. Chunyu Yi explained that when examining the pulse, he would feel $q i$ [coming] from the “liver" (gan 肝), the “heart" ( in 心), the “five viscera” (wu zang 五臟), the “water" (shui 水), the “wind” (feng 風), the "bladder" (pang guang 膀胱), the "lungs" ( $f e i$ 肺), the “spleen” ( $p i$ 脾), “worm-conglomerations” (jia 摭), and “penetrating wind” (nei feng 內風) (see table 2). In other words, Chunyu Yi would touch the mai and feel $q i$. So, qi was not an entity that could be seen but one that could be felt. 
Chunyu Yi could tactually perceive $q i$ in the mai. Notably, it was $q i$ that belonged to or came from one of the five viscera (the bladder was one of the five, mentioned in place of the kidneys), waters and winds, and worm conglomerations. In my Habilitation, by means of what I called the "structural analytic method," I have shown that these qualities of qi correlated with the name of the disorder. I will not expand on these details here, and merely point out that Shi ji 105 is the earliest extant text in Chinese medical history that puts mai, qi and the viscera in relation to each other: the tactile exploration of mai leads to the recognition of qi coming from the viscera.

Can we assume that $q i$ was flowing in the mai, in the way in which present-day practitioners speak of $q i$ flowing in the mai? There is no evidence from the twenty-five case histories in Shi ji 105 that qi was considered to flow in the mai. The expression " $q i$ flowing in the mai" emphasizes the aspect of $q i$ as matter, which flows inside a canal or channel, yet in the twenty-five case histories Chunyu Yi does not allude to such imagery. ${ }^{20}$ Rather, he seems to be emphasizing the agency of $q i$, its potential to induce transformations.

It is noteworthy that in nine out of ten cases (which deal extensively with pulse diagnostics), Chunyu Yi speaks of examining the mai and then feeling qi. However, once he speaks of jue yin zhi dong 踯陰之動 (case 10). In place of speaking in terms of viscera, he reverts to the cosmological terminology typical of the Mawangdui "vessel texts" and speaks of jue yin (attenuated yin), and instead of speaking of $q i$, he speaks of dong 動, which is best approximated as an agitation, an impulsion, an impulse, an irritation in the mai (Hsu 2001b). This suggests that Yi's use of the term qi refers not primarily to a substance that flows inside the mai but to a movement, an agitation, an irritation, a potential for change. ${ }^{21}$ Conversely, the use of $X z h i$ dong in place of $X q i$ informs us that both Chunyu Yi and the authors of the Mawangdui "vessel text" I.B, who said that if a vessel was "agitated, it would give rise to an illness" (shi dong ze bing 是動則病), had a very similar idea about illness causation. They both thought of illness being caused by some agitation, irritation or impulsion of/in the mai, although the "vessel text" authors did not use the term qi to speak of it.

Notably, it is only in the twenty-five case histories of Shi ji 105, where mai are seen as being connected to the viscera, that a physician by examining mai can perceive qi. This would suggest that speaking in terms of qi about agitations in the mai was only possible once the mai were conceived of as being linked to the viscera. I will expand on this observation in the following section.

To summarize the above, my argument built on verbally explicit and overwhelmingly rich material that had to be arranged with a rigorous imposition of structure. This was possible because I considered the twenty-five case histories to be written in a formulaic

\footnotetext{
${ }^{20}$ In the eight interview questions and answers, however, he arguably does. It is possible that the case histories need to be evaluated separately from the eight interview questions and answers.

${ }^{21} \mathrm{Q} i$ always encompasses both aspects: it is matter-agency or a substance-force, and in the above contexts the aspect of $q i$ as agency seems to be emphasized.
} 
format. It allowed me to discern two classes of adjectives for assessing qualities of "pulses" (mai). Furthermore, I suggested that the systematic tactile exploration of the mai made possible the perception of qi. It is noteworthy that the elaboration of different qualities of $q i$ happened in the context of a tactile exploration of a body part, namely that of mai. The systematization of the qualities of $q i$ consisted of its attribution to specific localities, the viscera (apart from the winds and waters, and conglomerations); this happened in a similar vein to the "vessel texts," where causes of "ailments" (bing) were systematically localized in the mai and "pain" (tong) in body parts. Admittedly, in Chunyu Yi's twenty-five case histories, the centrality of qi was observed particularly within the context of pulse diagnostics. However, qi acquired a far greater centrality in the later medical writings, such as the Nei jing, and in Chinese medical thinking in general.

\section{The tactile exploration of the abdomen}

It has to be borne in mind that in early Chinese medicine qi was not from the very start the kind of universal concept that reaches into remote regions of the Empire, and permeates the macrocosm of the universe and the microcosm of the body (Sivin 1995). As already said, the concept of qi was not central to the above discussed "vessel texts," but $q i$ was mentioned elsewhere in the Mawangdui medical corpus as, for instance, in the context of self-cultivation practices and sexual techniques (Lo 2001). Furthermore, qi occurred in the context of a medical treatment:

When the qi ascends and does not descend, discern which mai has excess and cauterise it at the ring [i.e. the ring around the waist]. If the ailment is severe, go up two cun above the ring and perform an additional cauterisation. If $q i$ starts oscillating, pierce the mai in the cavity at the back of the knees and in the cavity in front of the elbow with a stone needle. ${ }^{22}$

This well-known text passage links the manipulation of qi to needling. In the twenty-five medical case histories of Shi ji 105, notwithstanding the systematized qualities of $q i$ within the context of the pulse diagnostics that Chunyu Yi adhered to, qi is also mentioned in other contexts. Notably, Chunyu Yi treats the conditions that are explicitly characterized by an “inversion” ( jue 蹓) or an “amassment” (shan 疝) of qi and heat ( $r e$ by "needling” ( $c i$ 刺). In those cases qi does not appear to be the all-pervasive medium that permeates the body. Rather, it tends to be mentioned only when the patient subjectively feels “fullness” (man 滿) in “chest” ( $x$ in 心) or “abdomen” ( $u$ 腹).

\footnotetext{
22 Adopted from Harper 1998, 214, and Lo 2001, 29, and modified from Hsu 2001b, 85, all of whom based their translation on Ma 1992, 282. The text passage is badly damaged in the original and the translation above is based on the reconstruction of the text.
} 
Chunyu Yi speaks of "fullness" and “excess" ( you guo 有過), terms that later would designate a condition of repletion (Kuriyama 1999, 221). So, needling was advocated when there were oscillations, or inversions of $q i$ in chest or abdomen. Chunyu Yi speaks of $q i$ when there is an accumulation of it in the body trunk. If $q i$ in this narrow sense was tactually perceived, doctors of antiquity may have tactually explored the body surface of the abdomen for detecting accumulations of $q i^{23}$

In the context of discussing how the patient's feeling of "fullness" was associated with an accumulation of $q i$ in early Chinese medicine, it is worth mentioning that at the periphery of the Chinese cultural spheres, to the East in Japan and to the West in Tibet, contemporary doctors tactually explore the abdomen for diagnostic purposes (Young 2001). Interestingly, Japanese doctors, who perform diagnoses by palpating the hara, are interested in identifying jitsu repletions and kyo depletions (Adams 2003), concepts which, as just seen, relate primarily to the state of $k i$ in Japanese ( $q i$ in Chinese) and its excesses. ${ }^{24}$ It is indeed conceivable that these contemporary practices in culturally peripheral regions point to a practice of the center in former times. However, the observations of contemporary Tibetan and Japanese practices can only give us hints of what actually happened in ancient China.

As demonstrated above, Chunyu Yi could perceive the qualities of qi through tactile exploration of the surface of the body part mai. We also observed that in the "vessel texts," where the mai were not connected to the viscera, the language of qi was not used for describing agitations. Why did the language of qi start to be applied to vessel theory? Could it be that the notion of qi became important in medicine primarily in the context of speaking about visceral states? Was qi primarily considered to be stored in the viscera (I am aware that the aspects of $q i$ as matter are being emphasized if one phrases the question in this manner), and once the viscera were considered to be linked to the mai, could it be that the language of $q i$ then became part of vessel theory, and that qi eventually was conceived of as flowing in the vessels? If we assume that the viscera stored $q i$, and considering that the viscera were located in the chest and abdomen, it is conceivable that the corresponding body surface was tactually explored in order to know what the condition of qi in the viscera was. The question that then arises is why did physicians have the idea that viscera stored qi. In order to answer this question, one has to know more about the characteristics of the viscera in early Chinese literature.

In cross-cultural perspective, viscera are often conceived as the seats of emotion and feelings, and if the heart is considered a viscus, this view applies also to Chinese culture. The "heart" (xin) was the seat of emotions, moral sensitivities, thinking and ordering

\footnotetext{
${ }^{23}$ They may have tactually explored chest and abdomen. Yet in the light of the adjectives of touch they used (see below), which concern qualities of firmness and plasticity, it is conceivable that these qualities were felt particularly in the abdominal area.

${ }^{24}$ In the case histories of Shi ji 105, states of over exertion and exhaustion are extensively discussed, but $q i$ depletions are not explicitly mentioned.
} 
of the senses in the non-medical literature of pre-dynastic times (e.g. Sterckx 2003, 85). As far as a glance into the concordance of the "thirteen classics" (shi san jing 十三經) reveals, apart from the heart, none of the "five viscera" ( $w u z a n g$ ) was mentioned in close connection with a feeling. In the Nei jing, by contrast, the viscera are each associated with one of the feelings “anger” ( $n u$ 怒), “happiness” ( $x i$ 喜), “worry” (si 思), “sorrow” ( you 憂, bei 悲), or “fear” (kong 恐, jing 警). However, the correlation between a specific feeling and a specific viscus is fairly variable (Unschuld 2003, 227-234). This would suggest that the attribution of specific feelings to one of the five viscera was not firmly rooted in Han dynasty medicine.

In the twenty-five case histories of Shi ji 105, feelings are mentioned twice, once the feeling you, which usually is translated as "grief" but in case 2 probably means "anxiousness," and once the feeling of "anger" (nu), in case 6 (Shiki kaichû kôshô 史記會注考證 1934, 27 and 33). In those two cases, the feelings of grief and anger are given as reasons why the illness was contracted. This suggests that Chunyu Yi's illness etiology paid attention also to emotional and psychological states. Though it is not explicitly said, the text can be interpreted to convey that the feeling of you correlated with the "heart" or "chest" (xin) and that of $n u$ with the "liver" (gan) (Hsu 2001a, cases 2 and 6).

Is it possible that Chunyu Yi considered the two viscera heart and liver seats of emotion? This would suggest that in those contexts the body was viewed as bipartite, the heart was in the upper body region, the liver in the lower one. Such a partition of the body into upper and lower parts is reminiscent of the bodily bipartition invoked in the Mawangdui "vessel texts," with "forearm" and "foot" as categorizing devices for the mai (see above). It suggests that the numerology of two was an organizing principle for conceptualizing the body before that of five, as promulgated in the Su wen, became prevalent. It is noteworthy that xin (heart) and gan (liver) are also the only two viscera mentioned with certainty in the Mawangdui "vessel texts"; that is, if one takes seriously Ma Jixing's 馬繼興 $(1992,259)$ note that the character shen 腎 (kidney) is not mentioned in text I.B (CC 62), but another graph which has been interpreted to mean shen and that text I.A (CC 13) refers to other body parts in the corresponding position. When Chunyu Yi mentioned grief and anger as feelings that correlated with heart and liver, he may well have alluded to a bipartite conceptualization of the body. Probably he had no concept of "five natural inclinations" ( $w u$ xing zhi ti性志) or “seven feelings" ( $q i$ qing 七情), as later authors did, and therefore exhaustively used his repertoire when he mentioned only two.

In this context, I need to remark that the authors of the Mawangdui "vessel texts" did not primarily refer to xin as the seat of emotion and thought; rather, xin was used in a sense that referred to the architectural structure of the entire chest area and the epigastrium, and not only the heart. We are reminded of the fairly static architectural understanding of the body in those texts (for fuller discussion, see Hsu 2001a, case 9). The “vessel texts” mention xin tong 心痛 (chest pain or heart pain) and gan tong 肝痛 (liver pain), but xin tong does not refer to the heartache that the longing for someone 
Table 3. Adjectives of the tactile experience of palpating flesh and viscera Huang Di nei jing (1st-2nd century C.E.)

If the flesh is firm, then there is longevity (rou jian ze shou yi 剑整㺫素矣)

Ling shu 6, 285

The strength and weakness of sinews and bones, the firmness and plasticity of the flesh, the thickness and thinness of the skin, and the porosity and density of the skin pore pattern (jin gu zhi qiang ruo, ji rou zhi jian cui, pi fu zhi hou bo, cou li zhi shu mi

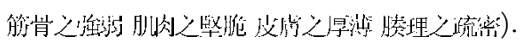

Ling shu 53, 408

If the lips are firm, the spleen is firm. If the lips while being large, are not firm, then the spleen is malleable (chun jian zhe, pi jian. chun da er bu jian zhe, pi cui 㨃堅者腮

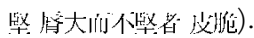

Ling shu 47, 393

If the five viscera are all firm, then there is no illness; if the five viscera are all soft, then one is ridden by illness (wu zang jie jian zhe, wu bing; wu zang jie cui zhe, bu li

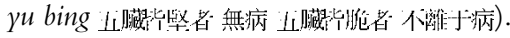

Ling shu 47, 394

causes, be it in a state of mourning or in one of being in love; nor is gan tong associated with anger.

It is noteworthy that in the Mawangdui "vessel texts" the rich vocabulary for body architectural structures enjoys great centrality, whereas in the "medicine of systematic correspondences" a vocabulary relating to the viscera becomes predominant. Could it be that, as interests of medical inquiry shifted, the viscera gained in importance for Han elite physicians? Could it be that this interest in visceral states arose as physicians became interested in emotional and psychological illness etiologies? Chunyu Yi, whose twenty-five case histories date to a period in between, paid attention to the emotional and psychological.

Irrespective of possible reasons $w h y$ physicians of antiquity should have explored the visceral states by palpating the abdomen, there are text passages which contain hints that they indeed did so (table 3). The text passages in question show that the same adjectives are used for assessing the quality of the "flesh" (rou 肉) and of the viscera. These adjectives are also mentioned in other text passages for describing the quality of the viscera, and for determining whether their state was healthy or not. ${ }^{25}$ The crux of the matter is that these adjectives referring to the "firm" (jian 堅) and "soft" or “tender" (cui 脆) were not only used for describing the visceral states, but also for the rou which is perhaps best approximated as the tonus of flesh and muscles. They are adjectives of touch, and they suggest that the qualities of muscle and flesh were

\footnotetext{
${ }^{25}$ Notably, the words of Ling shu 12 which were quoted above on page 3 referred to the "firmness and plasticity" (jian cui) of the viscera.
} 
established through touching them. In a similar vein, we may surmise, the qualities of the viscera, in particular those located in the abdomen, like the spleen, liver, or bladder (as outer aspect of the kidneys), were recognized by tactually exploring the abdominal body surface.

In this context, it is worth mentioning that there are several text passages that describe the tactual exploration of the abdominal region. Su wen 37, 108, for instance, describes how a pathological condition caused by moving coldness from the lungs to the kidneys results in "gushing water" (yong shui 涌水), which can be felt on the body surface, “when pressing on the abdomen, it is not firm” (an fu bu jian 按腹不堅). In other contexts, palpation of the abdomen refers to the identification of "conglomerations" (jia 猳) and “knots” (jie 結) (e.g. Ling shu 57, 414, and 75, 463). One is reminded that Chunyu Yi mentioned "conglomerations" in the same breath as the five viscera (see table 2), and does not seem to have considered them separate categories; their firmness may have been established by using the same diagnostic procedures of palpating the abdomen.

To summarize, I presented in this section indications that physicians of early Chinese medicine palpated not only the extremities and mai but also the abdomen. First, I pointed to contemporary diagnostic practices of abdominal palpation in Tibet and Japan, which provide hints that similar practices may once have been prevalent in China itself. Second, I noted that in Shi ji 105, when a patient complained of a feeling of "fullness," Chunyu Yi spoke of an "inversion" or an "amassment" of qi, and typically treated the patient with "needling." Since qi of the mai could be tactually perceived by "pressing" (qie) and "stroking" (xun), it is conceivable that an amassment of qi in the abdomen could be perceived by "palpation" (e.g. an). In the Nei jing, and in later medical writings (Shang han lun 傷寒論, Jin gui yao lüe 金臣要略) not discussed here, there are text passages that explicitly mention palpation of the abdomen. In those later medical texts, lumps and conglomerations were detected through palpation, but in Chunyu Yi's case histories, I suggest, an amassment of qi was just as tangible as a conglomeration of worms.

Third, I found that adjectives of touch, like "firm" and "soft," that were typically used for describing the tonus of muscle and flesh, were also used for describing the condition of the viscera. This would suggest that the condition of the viscera was ascertained through palpation, in particular, of the abdominal body surface. In other words, physicians in early Chinese medicine may well have engaged in tactile exploration of the abdomen in order to determine the firmness and plasticity of the "viscera."

I then went one step further. Perhaps the viscera were viewed as storage places of $q i$, just as they may have been storage places for emotions and feelings. There are two case histories in Shi ji 105 which suggest that the two main viscera of a bipartite body, the heart and the liver, correlated with the feelings of grief and anger. These two case histories suggest that Chunyu Yi's illness etiology also took account of the emotional and psychological. Rather than emphasizing the proto-anatomical aspect of the viscera, 
as many scholars of Chinese medicine have done, these two case histories enrich our understanding of the viscera by hinting at the possibility that physicians' interest in the emotional and psychological may have led to their increased interest in visceral conditions, which eventually became widely discussed in the "medicine of systematic correspondences."

\section{Discussion}

Our point of departure was that culture-specific medical knowledge depends on sensitivities and forms of perception that have to be learned. Anatomy, which laid the foundations for developments in modern bio-medicine is an edifice of knowledge gained largely, though not exclusively, from visual inspection. By contrast, the subtle changes, to which the Chinese "medicine of systematic correspondences" refers in the language of $q i$, are only indirectly perceptible by means of vision. This article sought to generate an understanding for why Chinese doctors of pre- and early dynastic times started to become interested in such subtle changes. I suggested that they systematically trained their tactility in order to detect these subtle changes.

First, Chinese physicians assessed "pain” (tong) by systematically localizing it in body parts, and I suggested that this mode of systematizing pain experiences may have been facilitated by pressing with hands on painful spots; second, they had a systematic vocabulary for assessing "impulsions" ( $q i$ and dong) indicative of disease, which could be detected by palpating the body part mai (vessel, duct, conduit); and third, they used adjectives of touch for assessing whether "viscera" (zang) were diseased or not, which suggests that visceral conditions were ascertained by tactually exploring the body surface, in particular, of the abdomen. These tactile explorations on a living body made Chinese physicians sensitive to aspects of human existence - pain, the pulses of life, and the tonus of flesh, muscles, and viscera - which are impossible to ascertain through a visual inspection of corpses.

\section{Postscript}

What are the implications of this finding, and how does it fit into existent work on the senses and sensory experience in China? While the literature on the senses, sensuality, and sensory experience has increased in recent years, in history (e.g. Harvey 2003) and anthropology (Howes 2003), one hesitates to transpose findings of EuroAmerican contexts into Chinese ones. Thus, in ancient Greece, touch was considered the "primary form of sense" that belonged to all animals (Aristotle, De Anima, cited in Lloyd 1996, 135). Touch and smell, in particular, due to the bodily proximity they involved, were subordinated to vision and hearing, senses which enabled perception at a greater distance (Synnott 1991). In the hierarchy of senses, vision became associated 
with the superior masculine, and touch with the inferior feminine (Classen 1997). In this way, touch became associated with the erotic and affective (Gilman 1993). On the other hand, touch has also been respected for the authoritative knowledge it generates and the divine powers it can transmit. While optical illusions are easily produced, veracity is often ascertained through touch: in the bible, Thomas did not trust his eyes when he saw Christ, who had been crucified and buried, he had to touch Christ's wounds to be assured of the veracity of resurrection (Immerwahr 1978); and in the Sistine Chapel, God, by touching Adam's finger, intends to transmit the breath of life (Boyle 1998).

Glen Mazis' observation that "the language of emotions is a tactile one" is worth mentioning in this context. He states: "It is interesting to note that emotions touch one, or that one feels this or that emotion" (Mazis 1979, 324; emphasis added). He points out how close the tactile is to the emotional: the word "closeness" for instance refers both to a physical and an emotional closeness, "touching" is "touching." Mazis' examples are taken from the English language, and clearly, no one would expect the understanding of emotions and emotionality to be identical in Western and Eastern contexts. It would be worth a study, however, to examine whether in literary Chinese the language of feelings and emotions was also a tactile one and how far such a linguistic interrelatedness between tactility and emotion may have had implications for the Chinese medical understanding of the body.

Shigehisa Kuriyama devoted an entire book to styles of touching, styles of seeing, and styles of being, in Greek and Chinese medicine, but nowhere suggested that tactility had primacy over vision among early Chinese medical doctors. There is no doubt that they made use of all their senses, vision included, though the material presented above would suggest that their tactility seems to have been particularly refined. Interestingly, this is also what, almost two millennia later, seventeenth-century travelers to China noticed as they "marvelled at the astonishing prowess of local healers, and especially at their exquisite feel of the pulse" (Kuriyama 1999, 21). Kuriyama suggests that Chinese sphygmology, with its flowery and fluid language, was "practiced confidently and flourished stably for over two thousand years," while physicians in the occidental medical traditions were intent on expunging the poetic, imaginative speech (ibid., 71). The twenty-seven standard Galenic pulses programmatically differentiated between length, width, and breadth of the pulses, whereas the twenty-four standard Chinese pulses testified to a wide range of adjectives of touch. Thus, although Kuriyama does not explicitly state the primacy of tactility over vision, the first two chapters suggest that pulse diagnostics flourished particularly among the Chinese.

Kuriyama then discusses styles of seeing. He points out that in illustrations of medical works there is a tendency to emphasize muscularity in the West, whereas "color" (se 色) was of primary concern to Chinese physicians. He explains that muscular will and wilfulness was celebrated in the West, while se was connected to the "imagery of flowering" (ibid., 186) and the growth of plants (ibid., 190). His argument is convincing, though it may be enriched with two further points. 
First, in non-medical contexts, there are Chinese scrolls that depict men and demons with muscle, while female bodies in the West, like Titian's Venus, are often luminescent white in color. This brings a gender aspect into Kuriyama's discussion. Perhaps, there are cross-culturally valid aspects of gender-relatedness in European and Chinese societies that relate men to muscularity and women to color and luminescence. Perhaps, certain cultural (medical) practices elaborate on masculine, or respectively, feminine, themes. For instance, tactility is intrinsic to maternal caring, and it enhances aspects of human existence central to child care. If luminescence and tactility were regarded as aspects of femininity, the Chinese medical body, much like the Taoist body (according to Schipper 1982), would have important characteristics of femininity.

The second point elaborates on Kuriyama's insight that, particularly in pre-dynastic texts, se need not mean color. He mentions the "hungry air" (ji se 慨色), the "joyful expression” (xi se 喜色), the “woeful mien” (you se 憂色) that occur in the Mengzi 孟子, and points out that only "eventually, with the rise of five-color/five-phase analysis, the association of se and color becomes fairly common" (ibid., 174). "Even so," Kuriyama continues, “the Han dynasty Shuowen 說文, the earliest Chinese dictionary, defines se as "...qi [that appears in] the forehead'." In this context, it is worth noting that historically diagnostics of mai and se developed together. Chunyu Yi does not only engage in pulse diagnostics, but also diagnoses se. If he had adhered to the Shuo wen's definition of se, and examined the mai for detecting $q i$, would he have examined the forehead for detecting " $q i$ on the forehead," i.e. se? Since he palpated the mai to detect $q i$, would he have palpated the forehead to detect qi? The fact of the matter is that Yi did not palpate the forehead, he "looked" (shi 祝) at patients, and “saw" (wang 望) their color (Shiki kaichû kôshô 1934, 40 and 41). Nevertheless, the idea is not entirely unfounded. There are adjectives in the Nei jing that qualify both, qualities of se and mai. One such adjective is $s e$ 溘, 澀 which means "rough" (incidentally it is a homophone of se 色 meaning "color"). One may ponder what a "rough" mai is, while it is easy to imagine that a "rough" se 色 refers to the feeling of a rough skin. Evidently, there are qualities that can be ascertained through visual as well as tactile investigation, like the smoothness and roughness of the skin. In this context, it is worth mentioning that historians of art have shown that sculpture was not always exclusively appreciated by contemplation; in some time periods, the conviction prevailed that it could only be fully apprehended through tactile exploration (Johnson 2002). Luminescence, which is an aspect of $s e$, is one such quality that can be visually and tactually comprehended.

Finally, let us turn to an article by Jean-Francois Billeter who was also intrigued by the "ocular metaphor" in the occident and, particularly, in Greek philosophy. $\mathrm{He}$ pointed to words like "idea," derived from eidos, eidolon, which means "image," or "theory," derived from theorein, to "look" (Billeter 1984, 26-7), and he stated that "in Chinese texts, the 'ocular metaphor' is remarkable, precisely, for its very absence" (translated from French, ibid., 34). However, he saw little sense in asking which of the senses may have predominated in Chinese cultures, and suggested rather, to oppose perception (visual perception, as known from ancient Greece), to "the act," "action," 
and "activity" among the ancient Chinese. In support of his argument, he cited the philosopher Zhuang Zhou’s 莊周 famous story about cook Ding 丁 who effortlessly cut an ox into pieces. Billeter remarks that in cook Ding's answer to Prince Wenhui 文惠, who had asked him how he had acquired such mastery, the crucial sentence was that his senses did not intervene with his actions anymore and that his heart-mind acted in its own accord and followed tian li 天理 ("les lineaments naturels"), the natural veining (ibid., 39). ${ }^{26}$ Billeter's point was that the Zhuangzi 莊子celebrated cook Ding's “action” of cutting up the ox, which relied on the heart-mind following the natural veining, and not on "perception" with the senses.

Billeter's viewpoint is challenged by Geaney, who in her monograph on The Epistemology of the Senses in Early Chinese Thought, provides several citations from thinkers recorded in the Xunzi 荀子, Mengzi, Mozi 黑子, Zhuangzi, and Lun $y u$ 論語 (Analects) that demonstrate that seeing and hearing, looking and listening, in interaction with each other, were thought to produce knowledge (Geaney 2002). Geaney did not explore how medical knowledge was thought to be generated, however. Since physicians, much like cooks, were craftsmen, Billeter's example of cook Ding's skill in cutting up an ox deserves further attention. For, regardless of what cook Ding said about himself and what the ancient Chinese philosopher of the Zhuang zi wished to convey to his readership, the outside observer will say that cook Ding, who used a knife that had cut up several thousand oxen without replacing it in nineteen years, truly had highly developed tactile sensitivities!

\section{Acknowledgments}

This article is based on my inaugural lecture, "Der ertastete Körper," at the University of Heidelberg on 11 December 2002. I presented an early version to the workshop on "The Body in Parts" at the London School of Economics in June 2001, an abbreviated version to the University of Aberdeen Chinese Studies Group in March 2003, and a thoroughly revised version to the Institute of Ethnology at the Academia Sinica of Taiwan in March 2004. I would like to thank the participants at the various occasions for their constructive criticism. I also thank David Howes, Katherine Morris, David Parkin, Roel Sterckx, and the four anonymous reviewers of Science in Context for valuable comments on earlier drafts. The research for writing the Habilitationsschrift was supported by the National Science Foundation of the United States in its early stages and the Swiss National Foundation in its later ones. I would never have embarked on the project without the unremitting encouragement and support from Geoffrey Lloyd.

\footnotetext{
${ }^{26}$ In Graham's translation, the text passage reads: "Nowadays, I am in touch through the daemonic in me, and do not look with the eye ... I rely on Heaven's structuring [tian li], cleave along the main seams, let myself be guided by the main cavities, go by what is inherently so" (Graham 1981, 63-4). See also Zhuang zi, 119.
} 


\section{References}

Adams, G. 2003. "Shiatsu in Britain and Japan: Personhood, Holism and Embodied Aesthetics." Special Issue, Countervailing Creativity: Patient Agency in the Globalisation of Asian Medicines, edited by E. Hsu and E. Høg. Anthropology and Medicine 9(3):245-266.

Andrews, B. J. 1994. "Tailoring Tradition: The Impact of Modern Medicine on Chinese Traditional Medicine, 1887-1937." In Notions et perceptions de changement en Chine, edited by V. Alleton and A. Volkov, 149-166. Paris: Collège de France, Institut des Hautes Etudes Chinoises.

Autton, N. 1989. Touch: an Exploration. London: Darton, Longman and Todd.

Billeter, J.-F. 1984: "Pensée occidentale et pensée chinoise: le regard et l'acte." In Différences, valeurs, hiérarchie. Texts offerts à Louis Dumont, edited by J.-C. Galey, 25-51. Paris: Editions de l'Ecole des Hautes Etudes en Sciences Sociales.

Boyle, M. O'Rourke. 1998. Senses of Touch: Human Dignity and Deformity from Michelangelo to Calvin. Leiden: Brill.

Bridgman, R. F. 1981. "Les fonctions physiologiques chez l'homme dans la Chine antique." History and Philosophy of the Life Sciences 3(1):3-30.

Classen, C. 1997. "Engendering Perception: Gender Ideologies and Sensory Hierarchies in Western History." Body and Society 3(2):1-18.

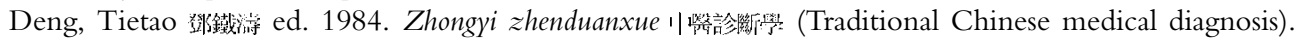
Shanghai: Shanghai kexue jishu chubanshe.

Despeux, C., ed. Forthcoming: Médecine, religion et société dans la Chine médiévale. Les manuscrits médicaux de Dunhuang.

Foucault, M. [1963] 1989. The Birth of the Clinic. London: Routledge.

Furth, C. 1999. A Flourishing Yin: Gender in China's Medical History, 960-1665. Berkeley: University of California Press.

Geaney, J. 2002. On the Epistemology of the Senses in Early Chinese Thought. Honolulu: University of Hawaii Press.

Gilman, S. 1993. "Touch, Sexuality and Disease." In Medicine and the Five Senses, edited by W. F. Bynum and R. Porter, 198-224. Cambridge: Cambridge University Press.

Good, M.-J. et al., eds. 1992. Pain as Human Experience: an Anthropological Perspective. Berkeley: University of California Press.

Graham, A. C. 1981. Chuang-tzu: the Inner Chapters. London: Allen and Unwin.

Graham, A. C. 1986. Yin -yang and the Nature of Correlative Thinking. Institute of East Singapore: Asian Philosophies.

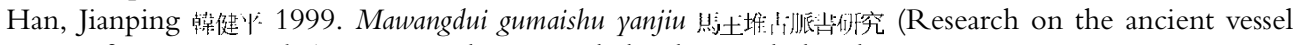
texts from Mawangdui). Beijing: Zhongguo shehui kexue chubanshe.

Harper, D. 1998. Early Chinese Medical Literature: the Mawangdui Medical Manuscripts. London: Kegan Paul International.

Harvey, E. D., ed. 2003. Sensible Flesh: on Touch in Early Modern Culture. Philadelphia: University of Pennsylvania Press.

He, Z. G. and V. Lo. 1996. "The Channels: a Preliminary Examination of a Lacquered Figurine from the Western Han Period.” Early China 21:81-123.

Howes, D. 2003. Sensual Relations: Engaging the Senses in Culture and Social Theory. Ann Arbor: University of Michigan Press.

Hsu, E. 1993/94. "Schmerz, Individuum und Gemeinschaft." In Les frontières du mal: approaches anthropologiques de la santé et de la maladie, edited by M.-O. Gonseth. Ethnologica Helvetica 17-18:65-74.

Hsu, E. 2000. "Towards a Science of Touch, part I and II." Anthropology and Medicine 7(2 and 3):251-269 and 319-333. 
Hsu, E. 2001a. The Telling Touch: Pulse Diagnostics in Early Chinese Medicine, with Translation and Interpretation of Ten Medical Case Histories of Shi ji 105.2 (ca 90 BC). Habilitationsschrift in Sinologie, Fakultät für Orientalistik und Altertumswissenschaft, Universität Heidelberg.

Hsu, E. 2001b. "Pulse Diagnostics in the Western Han: How mai and qi determine bing." In Innovation in Chinese Medicine, edited by E. Hsu, 51-91. Cambridge: Cambridge University Press.

Hsu, E. 2001c. "Figuratively Speaking of the Danger of Death in Chinese Pulse Diagnostics." In The History of Unconventional Medicine: Approaches, Concepts, Case Studies, edited by R. Jütte and M. Eklöf, 193-210. Sheffield: European Association for the History of Medicine and Health Publications.

Immerwahr, R. 1978. "Diderot, Herder, and the Dichotomy of Touch and Sight." Seminar 14:84-96.

Jackson, J. 1992. “ “After a While No One Believes You': Real and Unreal Chronic Pain.” In Pain as Human Experience: an Anthropological Perspective, edited by M.-J. Good et al., 138-168. Berkeley: University of California Press.

Jackson, J. 1994. "Chronic Pain and the Tension between the Body as Subject and Object." In Embodiment and Experience: the Existential Ground of Culture and Self, edited by T. Csordas, 201-228. Cambridge: Cambridge University Press.

Johnson, G. A. 2002. "Touch, Tactility, and the Reception of Sculpture in Early Modern Italy." In $A$ Companion to Art Theory, edited by P. Smith and C. Wilde, 61-74. Oxford: Blackwell.

Keegan, D. J. 1988. “The 'Huang-ti Nei-Ching': the Structure of the Compilation; the Significance of the Structure." Ph.D. thesis. University of California, Berkeley.

Kuriyama, S. 1999. The Expressiveness of the Body, and the Divergence of Greek and Chinese Medicine. New York: Zone Books.

Legge, J. [1871] 1991. The Chinese Classics. Vol. 5. Taipei: SMC Publishing.

Li, Ding 李㭊 ed. 1984. Jingluoxue 經絡齐 (The study of the channels and links). Shanghai: Shanghai kexue jishu chubanshe.

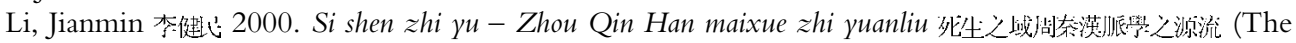
rhyming of life and death - the origins of vessel theory in the Zhou, Qin, and Han periods). Taipei: Zhongyang yanjiuyuan lishi yuyan yanjiusuo.

Lloyd, G. E. R. 1970. Early Greek Science: Thales to Aristotle. New York: W. W. Norton.

Lloyd, G. E. R. 1996. Aristotelian Explorations. Cambridge: Cambridge University Press.

Lo, V. 2001. "The Influence of Nurturing Life Culture on the Development of Western Han Acumoxa Therapy." In Innovation in Chinese Medicine, edited by E. Hsu, 19-50. Cambridge: Cambridge University Press.

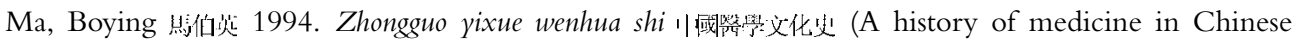
culture). Shanghai: Shanghai renmin chubanshe.

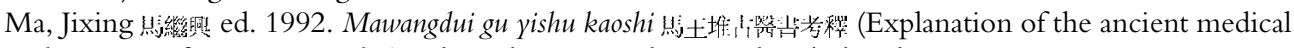
documents from Mawangdui). Changsha: Hunan kexue jishu chubanshe.

Martin, J. 1988. "Scopic Regimes of Modernity." In Vision and Visuality, edited by H. Foster, 3-23/27. Seattle: Bay Press.

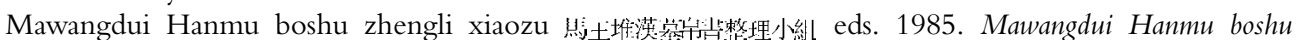

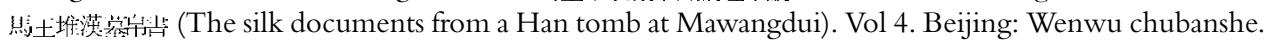

Mazis, G. A. 1979. "Touch and Vision: Rethinking with Merleau-Ponty Sartre on the Caress." Philosophy Today 23(4):321-328.

McKnight, B. E. 1981. The Washing Away of Wrongs, Sung Tz'u. Ann Arbor: Center for Chinese Studies, University of Michigan.

Melzack, R. and P. Wall. 1982. The Challenge of Pain. Harmondsworth: Penguin.

Merleau-Ponty, M. [1945] 1962. The Phenomenology of Perception. London: Routledge and Kegan Paul.

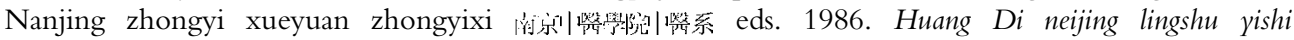

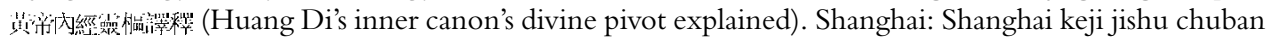
she. 
Porkert, P. 1974: The Foundations of Chinese Medicine: Systems of Correspondence. Cambridge, Mass.: MIT Press.

Pugh, J. F. 1991. "The Semantics of Pain in Indian Culture and Medicine." Culture, Medicine, and Psychiatry 15(1):19-43.

Rifkin, J. 2002. Science in the Age of Sensibility: the Sentimental Empiricists of the French Enlightenment. Chicago: University of Chicago Press.

Schipper, K. 1982. Le corps Taoiste. Corps physique - corps social. Paris: Fayard.

Shapin, S. 1994. A Social History of Truth. Civility and Science in Seventeenth-Century England. Chicago: University of Chicago Press.

Sivin, N. 1993. Huang ti nei ching. In Early Chinese Texts: a Bibliographical Guide, edited by M. Loewe, 196215. Berkeley: Society for the Study of Early China and the Institute of East Asian Studies, University of California.

Sivin, N. 1995. "State, Cosmos, and Body in the Last Three Centuries B.C." Harvard Journal of Asiatic Studies 55(1):5-37.

Sterckx, R. 2003. "Le pouvoir des sens: sagesse et perception sensorielle en Chine ancienne." In $D u$ pouvoir, edited by R. Lanselle, 71-92. Paris: Presses Universitaires de France.

Synott, A. 1991. "Puzzling over the Senses: From Plato to Marx." In The Varieties of Sensory Experience: a Sourcebook in the Anthropology of the Senses, edited by D. Howes, 61-76. Toronto: University of Toronto Press.

Unschuld, P. U. 1980. Medizin in China. Eine Ideengeschichte. München: Beck.

Unschuld, P. U. 1986. The Classic of Difficult Issues. With Commentaries by Chinese and Japanese Authors from the Third through to the Twentieth Century. Berkeley: University of California Press.

Unschuld, P. U. 2003. Huang Di nei jing su wen. Nature, Knowledge, Imagery in an Ancient Chinese Medical Text. Berkeley: University of California Press.

Young, J. 2001. Eastern Healing: the Practical Guide to the Healing Traditions of China, India, Tibet, and Japan. London: Duncan Baird.

Yunnan zhongyi xueyuan Shanghai: Shanghai kexue jishu chubanshe.

\section{Premodern sources}

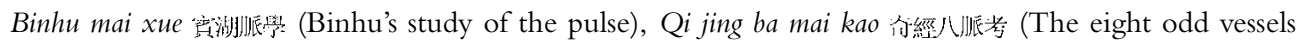
examined), Mai jue kao zheng 振洪考泣l: (The rhymed canon of sphygmology examined). Ming, 1564. Li Shizhen 有脟飨. Reprint 1956. Beijing: Renmin weisheng chubanshe.

Han shu 漢肯 (History of the former Han). Han, 1st c. C.E. Ban Gu 理凩. Reprint 1962. Beijing: Zhonghua shuju.

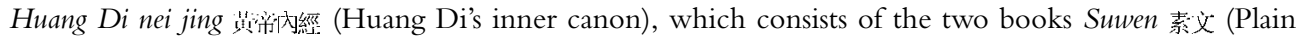

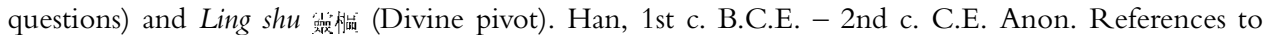

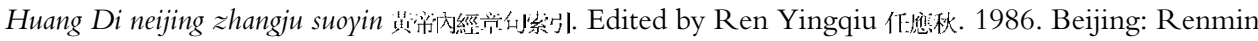
weisheng chubanshe.

Mai jing 挀經. (Canon of sphygmology). Jin, 280 C.E. Wang Xi 土熙. References to Maijing jiaozhu 挀經校拄: Annotated by Shen Yannan 沈炎佣. 1991. Beijing: Renmin weisheng chubanshe.

Shi ji 尖記 (Records of the historian). Han, c. 90 B.C.E. Sima Qian 间悲選. Reprint 1959. Beijing: Zhonghua shuju.

Shiki kaichû kôshô 这記命注考證 (Examination of the collected commentaries to the records of the historian). 1932-1934. Commented by Takigawa Kametaro 㴰川鵤太郎. Tokyo: Toyo Bunka Gakuin.

Zhuang zi yil: (Master Zhuang). Zhou to Han, 4th-2nd c. B.C.E. Zhuang Zhou Hilin. References to

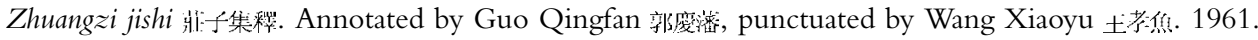
Beijing: Zhonghua shuju. 